\title{
The Prevalence of Gallstones in Gastrectomized Patients: A Comparative Study in a Large Population
}

\author{
Kose SEgawa, Yasumasa Niwa, Tomiyasu ARISAwa, Takashi SuzUKI, \\ Hidemi GOTO*, Shinji OHASHI*, Takeshi TsUCHIDA* and Yoshihisa TSUKAMOTO*
}

\begin{abstract}
We investigated the prevalence of gallstones after gastrectomy by abdominal ultrasonography in 289 gastrectomized patients selected from 51,621 Automated Multiphasic Health Testing and Services (AMHTS) examinees after barium meal studies. The results were compared with those of another group of 3,193 AMHTS patients who routinely underwent ultrasonography (control). Among the gastrectomized patients, the overall prevalence of gallstones was $16.6 \%$, and in the control group, $4.7 \%$, showing a statistically significant difference $(p<0.001)$. The prevalence of gallstones increased with age in both the control and gastrectomized groups, but was greater in gastrectomized subjects in each (10-yr) age group. The characteristics of the gallstones were compared between gastrectomized patients and the control group according to the ultrasonographic classification proposed by Tsuchiya (Yazawa et al, Jpn J Gastroenterol 85: 708, 1988). In the control group, the percentages of types I, II, III and small stone of Tsuchiya's classification were 30.2, 14.5, 21.9 and 34.3, respectively. On the other hand, in the gastrectomized group, the percentages were $8.3,6.3,16.7$ and 68.8 , respectively. This difference was statistically significant $(p<0.001)$. The differences in the prevalence of gallstones between groups with Billroth I and II anastomoses, and between diseases necessitating gastrectomy, were not statistically significant.
\end{abstract}

Key words: Cholelithiasis, Gastric surgery, Abdominal ultrasonography, AMHTS

Following gastric resection, various disturbances are known to occur in the digestive system and sometimes cause problems throughout the body. Many sequelae, such as anemia, malnutrition and the dumping syndrome are known to be associated with gastric resection (1). Some of these sequelae are the result of a disturbance in the absorption of intestinal contents, because with gastrectomy, gastric acid secretion is lost and secondary changes in bacterial flora occur in the small intestine. Gallstones are known to be a complication of gastric surgery (2).

In 1947, Majoor and Suren (3) were the first to report the close relationship between gallstones and gastric resection in clinical cases. Since then, there have been various reports concerning clinical cases
$(4,5)$ and etiology $(6,7)$. In relation to the latter, many investigators have emphasized the significance of the disturbed contraction of the gallbladder due to vagotomy $(8,9)$. Some investigators examined the prevalence $(10,11)$ of gallstones associated with gastric surgery; an increased prevalence of gallbladder calculi in post-gastrectomy patients was a uniform finding.

However, in the former studies, the methods of gallstone diagnosis were not uniform, and the age of patients studied, type of operation performed and follow-up period after surgery all were varied. Thus, the results differed in certain aspects. Moreover, in a recent paper, Chaoui and Reinbacher (12) examined 28,204 autopsies reports to determine the prevalence of all forms of cholecystitis in patients

From Department of Gastroenterology, Aichi Prefectural Center for Health Care, Nagoya and *Second Department of Internal Medicine, Nagoya University School of Medicine, Nagoya

Received for publication June 11, 1990; Accepted for publication January 14, 1991

Reprint requests should be addressed to Kose Segawa, MD, Department of Gastroenterology,

Aichi Prefectural Center for Health Care, 3-2-1 San-no-maru, Naka-ku, Nagoya 460, Japan 
suffering from peptic ulcer and following partial resection. They reported finding no statistically significant difference in the prevalence of gallstone formation among them. Thus, the true prevalence of gallbladder calculi associated with stomach surgery has not been established.

The recent advances in abdominal ultrasonography have facilitated easy detecting of gallbladder disease without the use of invasive procedures. Our institute performs very precise multiple examinations on a large, apparently healthy population to verify the maintenance of health before any symptoms appear. Examinees amount to more than 25,000 a yr, and more than 3,500 of them undergo ultrasonography. The present study was conducted to compare the age-dependent changes in gallstones detected by ultrasonography and gallstone characteristics in postgastrectomy patients compared with those in an apparently healthy population. The etiology of gallstones is also discussed as a sequelae of gastric resection.

\section{MATERIALS AND METHODS}

\section{Subjects}

At our institute, Automated Multiphasic Health Testing and Services (AMHTS) is divided into two courses, Course A and B. The gastrectomized patients were selected from examinees of Course A of our AMHTS from February 1988 to June 1990. They underwent AMHTS before any symptoms appeared. Examinations included radiography of the upper gastrointestinal tract, but not abdominal ultrasonography. In the barium meal study of upper gastrointestinal tract of subjects who had undergone gastrectomy, abdominal ultrasonographic examination was performed when the informed consent of the subject was obtained. The total number of AMHTS Course A subjects during the period of this investigation totaled 51,$621 ; 289$ gastrectomized patients underwent abdominal ultrasonography. The age of these gastrectomized patients ranged from 33 to $83 \mathrm{yr}$, and the mean age \pm SD was $55.30 \pm 9.45$ yr. The age distribution is shown in Table 1. The major diseases that necessitated gastrectomy included gastric cancer (83 cases), duodenal ulcer (87), gastric ulcer (98) and gastroduodenal ulcer (7). However, in 14 patients disease leading to the gastrectomy was not known. Anastomosis after gastric resection was performed by Billroth I and Billroth II techniques; the ratio of the former technique to the latter being 3:2. The number of years after gastrectomy ranged from less than $1 \mathrm{yr}$ to $41 \mathrm{yr}$, with a mean \pm SD of $13.66 \pm 9.14 \mathrm{yr}$. The distribution of the number of postsurgical years is shown in Table 2.

The control group consisted of 3,551 Course B AMHTS subjects examined from January to December 1988. All routinely underwent abdominal ultrasonography to detect gallbladder, pancreas, kidney, spleen, and liver diseases before the appearance of any symptoms like the subjects of Course A. The age distribution of the control group is shown in Table 1. There was no statistically significant difference in the age distribution between the

Table 1. Age-dependent change in the prevalence $(\%)$ of GB stones patients in control \& gastrectomized groups.

\begin{tabular}{|c|c|c|c|c|c|c|c|}
\hline \multirow{2}{*}{$\begin{array}{l}\text { Age } \\
\text { Group }\end{array}$} & \multicolumn{3}{|c|}{ Gastrectomized } & \multicolumn{3}{|c|}{$\begin{array}{l}\text { Control } \\
\text { (Course B) }\end{array}$} & \multirow[b]{2}{*}{$\mathrm{p}$ values } \\
\hline & $\mathrm{n}$ & GB stones & $\%$ & $\mathrm{n}$ & GB stones & $\%$ & \\
\hline$-39 \mathrm{yr}$ & 14 & 2 & 14.3 & 554 & 10 & 1.8 & $\mathrm{p}<0.05$ \\
\hline$-49 \mathrm{yr}$ & 68 & 9 & 13.2 & 1,355 & 49 & 3.6 & $\mathrm{p}<0.001$ \\
\hline$-59 \mathrm{yr}$ & 106 & 16 & 15.1 & 1,143 & 61 & 5.3 & $\mathrm{p}<0.001$ \\
\hline$-69 \mathrm{yr}$ & 79 & 16 & 20.3 & 425 & 36 & 8.5 & $\mathrm{p}<0.001$ \\
\hline $70 \mathrm{yr}-$ & 22 & 5 & 22.7 & 74 & 10 & 13.5 & ns \\
\hline Total & 289 & 48 & 16.6 & 3,551 & 166 & 4.7 & $\mathrm{p}<0.001$ \\
\hline
\end{tabular}

$\mathrm{n}$ : number of subjects; GB stone: number of gallstones patients; $\%$ : prevalence of gallstones; $\mathrm{p}$ value: by chi-square test. 
Table 2. Number of postsurgical years in gastrectomized group.

\begin{tabular}{lr}
\hline $\begin{array}{l}\text { Postsurgical } \\
\text { interval }\end{array}$ & $\mathrm{n}$ \\
\hline $1 \mathrm{yr}$ or less & 13 \\
$-3 \mathrm{yr}$ & 26 \\
$-6 \mathrm{yr}$ & 38 \\
$-9 \mathrm{yr}$ & 36 \\
$10 \mathrm{yr}$ or more & 176 \\
\hline Total & 289 \\
\hline
\end{tabular}

control group and gastrectomized patients by the chi square test.

\section{Method/gallstone diagnosis}

Abdominal ultrasonography (Sonolayer-V SSA-90A, Toshiba Co, Ltd., Tokyo, Japan) was performed initially to detect gallstones. When any signs were found and confirmation of diagnosis or further examinations were required, additional examinations such as abdominal CT, endoscopic ultrasonography or drip-infusion cholangiography were performed.

\section{Statistics}

The chi-square test was performed to compare the prevalence among groups and Student's t-test was used to compare the parametric data. Differences were considered statistically significant when $\mathrm{p}<0.05$.

\section{RESULTS}

The prevalence of gallstones in gastrectomized and control subjects increased with age, but was greater in gastrectomized patients in every age group except in the group older than $70 \mathrm{yr}$ with statistical significance $(\mathrm{p}<0.05$ in the youngest group and $\mathrm{p}<0.001$ in the other groups) (Table 1). Thus, gallstones were found in 48 of 289 gastrectomized patients and the overall prevalence was $16.6 \%$. In the control group, gallstones were found in 166 subjects, with an overall prevalence of $4.7 \%$. The difference between the groups was statistically significant $(\mathrm{p}<0.001)$.

The characteristics of the gallstones were compared between gastrectomized patients and the control group according to the ultrasonographic images
Table 3. Tsuchiya's classification of ultrasonographic image of GB stone in control \& gastrectomized groups.

\begin{tabular}{lrrrrr}
\hline & \multicolumn{2}{c}{$\begin{array}{c}\text { Gastrec- } \\
\text { tomized }\end{array}$} & & \multicolumn{2}{c}{ Control } \\
\cline { 2 - 3 } \cline { 5 - 6 } $\begin{array}{l}\text { Tsuchiya's } \\
\text { classif. }\end{array}$ & $\mathrm{n}$ & $\% 0$ & & $\mathrm{n}$ & $\%$ \\
\hline I & 4 & 8.3 & & 50 & 30.2 \\
II & 3 & 6.3 & & 24 & 14.5 \\
III & 8 & 16.7 & & 35 & 21.9 \\
Small stones & 33 & 68.8 & & 57 & 34.3 \\
\hline Total & 48 & 100 & 166 & 100 \\
\hline
\end{tabular}

$\mathrm{p}<0.001$ by the chi square test

of gallstones classified into types I, II, III and small stone using the classification of Yazawa, Tsuchiya et al (13). In the control group, the percentages of types I, II, III and small stones were 30.2, 14.5, 21.9 and 34.3 , respectively. On the other hand, in the gastrectomized group, the percentages were 8.3, 6.3, 16.7 and 68.8 , respectively. This difference between groups was statistically significant $(\mathrm{p}<0.001)$. Thus, the percent of small stones in the gastrectomized group was approximately two times greater than that of the control group (Table 3).

The prevalence of gallstones in gastrectomized subjects was compared between the groups undergoing Billroth I and in Billroth II anastomoses. There was no difference between the groups in the age of patients, although the postsurgical years in the Billroth II group was significantly greater than that in the Billroth I group $(\mathrm{p}<0.001)$. In the group with Billroth I anastomosis, the prevalence of gallstones was $15.2 \%$ and in Billroth II, $18.4 \%$, such that there was no statistically significant difference between the two groups (Table 4).

The prevalence of gallstones was compared among the major diseases (gastric cancer, duodenal ulcer and gastric ulcer) leading to gastrectomy, but no statistically significant differences were found (Table 5).

\section{DISCUSSION}

In our institute, AMHTS is divided into two courses, Course A and B, in order to fulfill various examination objectives. The examinees of Course 
Table 4. GB-Stones in gastrectomized subjects with Billroth I and II anastomoses.

\begin{tabular}{lccl}
\hline & Billroth I & Billroth II & p values \\
\hline Number of subjects & 171 & 114 & - \\
Age (yr) & $55.1 \pm 9.5$ & $55.4 \pm 9.6$ & $\mathrm{~ns}$ \\
Postsurgical years & $11.8 \pm 8.6$ & $16.9 \pm 9.1$ & $\mathrm{p}<.0 .001$ \\
Patients with GB stones & 26 & 21 & - \\
Prevalence of stones & $15.2 \%$ & $18.4 \%$ & $\mathrm{~ns}$ \\
\hline
\end{tabular}

Years are expressed as mean $\pm \mathrm{SD}$. Four patients receiving total gastrectomy were excluded from this table.

Table 5. Diseases necessitating gastrectomy and prevalence of GB stones.

\begin{tabular}{|c|c|c|c|c|}
\hline & \multicolumn{3}{|c|}{ Disease preceding gastrectomy } & \multirow[b]{2}{*}{$\mathrm{p}$ values } \\
\hline & $\mathrm{Ca}$ & DU & GU & \\
\hline No. of subjects & 83 & 87 & 98 & - \\
\hline Age (yr) & $57.6 \pm 8.1$ & $52.4 \pm 8.6$ & $56.6 \pm 10.8$ & ns \\
\hline Postsurg. yr & $6.4 \pm 5.3$ & $16.7 \pm 8.3$ & $16.8 \pm 9.1$ & $\mathrm{p}<0.001 \mathrm{Ca}$ vs $\mathrm{DU} \& \mathrm{GU}$ \\
\hline Pts with stone & 13 & 16 & 14 & - \\
\hline Prevalence & $15.7 \%$ & $18.4 \%$ & $14.3 \%$ & ns \\
\hline
\end{tabular}

Ca, Gastric cancer; DU, Duodenal ulcer; GU, Gastric ulcer. Years are expressed as mean \pm SD. Disease diagnoses were not known in 14 patients.

A as well as those of Course B come to us for a health check-up before any apparent symptoms appear. In the Course A group, the examinations cover ECG, chest radiography, blood chemistry, UGI series, spirometry, eye fundus, body scaling (body wt and ht), serological tests, etc., but do not include ultrasonography. The details have already been reported in our previous paper (14). The examinations of Course B are almost the same. In Course A, however, the focus is on the upper gastrointestinal tract, whereas in Course B, it is on the pancreatico-biliary system. Thus, all of the Course A subjects undergo a barium meal study, but not ultrasonography, and those in course B undergo abdominal ultrasonography but not a barium meal study. The examinees at our institute are recommended to undergo the examinations of both courses alternatively. The patients history of both groups is similar. In the present study, the gastrectomized patients were thus selected from Course A examinees, and underwent abdominal ultrasonography at random when they gave informed consent.
The prevalence of gallstones was compared between the gastrectomized group and the control group. The prevalence of gallstones increased with age both in gastrectomized patients and in controls, but it was greater in the gastrectomized patients in every age group. Thus, postgastrectomy gallstones were relatively common.

After Billroth II anastomosis, the contents of the stomach bypass the duodenum to enter the jejunum, whereas after Billroth I anastomosis they move from the stomach to the duodenum physiologically. When the food in the stomach enters the duodenum, cholecystokinin (CCK) is liberated and induces the contraction of the gallbladder (15). The movement of the food and the contraction of the gallbladder are very closely related. However, we found no difference in the prevalence of gallstones depending on the mode of gastric anastomosis.

The contractile motility of the gallbladder is regulated by neural and humoral factors (15), and the etiology of gallstones following gastric resection has been elucidated on the basis of both factors. 
Johnson and McDermott (16) reported that, in both the fasting and the postprandial states, CCK-PZ levels are significantly lower in gastrectomized patients than in healthy controls. Sapala et al (11) studied the prevalence of gallstones in two groups of patients gastrectomized for peptic ulcer with and without bilateral vagotomy. They reported it to be $6 \%$ in the group without vagotomy and $21 \%$ in the group with vagotomy. Satake et al (17) measured endogenous cholecystokinin release after a test meal in controls, and in gastrectomized patients with Billroth I and II anastomoses, but differences in integrated cholecystokinin secretion in these groups were not significant. Takahashi et al (18) compared contractile motility in patients who had undergone gastrectomy after oral administration of dried egg yolk. The contractile motility was markedly impaired, especially in the gastric cancer patients.

In the present study, the prevalence of gallstones was compared among the patients gastrectomized because of peptic ulcer and gastric cancer on the basis of the assumption that cancer surgery is more invasive than peptic ulcer surgery. However, no significant difference was seen. Thus, the hypomotility of the gallbladder contraction after gastrectomy was due to various mechanical anatomical changes resulting from the surgery, and the etiology of gallstones may be related to the disrupted contraction of the gallbladder resulting from various physiological and anatomical mechanisms.

Yazawa (13) reported qualitative analysis of gallstones based on their ultrasonographic properties, and classified the ultrasonographic images of gallstones into types I, II, III and small stones. This classification has been called Tsuchiya's classification and has been widely used among Japanese gastroenterologists. According to their report (13), type I comprises pure cholesterol stone, mixed stone and combination stone; type II, mixed stone and combination stone; type III, pigment stone; and small stones, mixed stone, combination stone and pigment stone. The dominant rate of small stones in the gallstones of gastrectomized patients suggests an etiology of gallstones formation which differs from that of control group.

The question arises as to how many years are required after surgery for the formation of gallstones.
The authors attempted to consider the relationship between the time after surgery and the prevalence of gallstones. However no definitive answer to this question could be elucidated from the present study due to the uneven distribution of the postsurgical intervals. To answer this question clearly, a followup study beginning just after surgery must be conducted. As stated earlier, a method for preventing gallstones is imperative for cases in which gastric surgery is performed. At present, however, an ultrasonographic examination is essential for followup studies of patients undergoing gastrectomy.

ACKNOWLEDGMENTS: We thank Takashi Kubota and other members of the Department of Radiology of the Aichi Prefectural Center for Health Care for their assistance in this study. We are also grateful to Masahiro Oda, a member of the electronic computer room staff, for the preparation of clinical data.

\section{REFERENCES}

1) Stabile BE, Passaro E. Sequelae of surgery for peptic ulcer, Chap 73. in: Bockus Gastroenterology (4th ed.) Berk JE, Ed. WB Saunders, Philadelphia, 1985.

2) Fletcher DM, Clark CG. Gall-stones and gastric surgery. A review. Br J Surg 55: 895, 1968.

3) Majoor CLH, Suren ThJJ. Gall-bladder complications following resection of stomach for peptic ulcer. Br Med J II: 8,1947 .

4) Horwitz A, Kirson SM. Cholecystitis and cholelithiasis as a sequel to gastric surgery. A clinical impression. Am J Surg 109: 760, 1965.

5) Griffith JMT, Holmes G. Cholecystitis following gastric surgery. Lancet II: 780, 1964.

6) Hopman WPM, Jansen JBMJ, Lamers CBHW. Plasma cholecystokinin response to oral fat in patients with Billroth I and Billroth II gastrectomy. Ann Surg 199: 276, 1984.

7) Inoue K, Huang YS, Seino Y, et al. Release of cholecystokinin and gallbladder contraction before and after gastrectomy. Ann Surg 205: 27, 1987.

8) Ihasz M, Griffith CA. Gallstone after vagotomy. Am J Surg 141: 48, 1981.

9) Shaffer EA. The effect of vagotomy on gallbladder function and bile composition in man. Ann Surg 195: 413, 1982.

10) Lundman $T$, Orinius $E$, Thorsen $G$. Incidence of gallstone diseases following partial gastric resection. Acta Chir Scand 127: 130, 1984.

11) Sapala MA, Sapala JA, Soto ADR, et al. Cholelithiasis following subtotal gastric resection with truncal vagotomy. Surg Gyn Obst 148: 36, 1979.

12) Chaoui VZ, Reinbacher L. Cholelithiasis nach Magenresektion? Zbl Chirurgie 107: 1201, 1982 
(abstract in English).

13) Yazawa $T$, Tsuchiya $Y$, Saisho $H$, et al. Qualitative analysis of gallstones based on their ultrasonic properties. Jpn J Gastroenterol 83: 708, 1988 (in Japanese).

14) Segawa $K$, Nakazawa $S$, Yamao $K$, et al. Age- and sexdependent changes in serum amylase in apparently healthy population. Am J Gastroenterol 84: 514, 1989.

15) Ryan JP. Motility of the gallbladder and biliary tree. in: Physiology of the Gastrointestinal Tract, Johnson LR, Ed. Raven Press, New York, 1981.
16) Johnson AG, McDermott SJ. Sensitive bioassay of cholecystokinin in human serum. Lancet II: 589, 1973.

17) Satake $K$, Takeuchi $T$, Watanabe $S$, et al. Postprandial plasma cholecystokinin response in patients after gastrectomy and pancreatoduodenectomy. Am J Gastroenterol 81: 1038, 1986.

18) Takahashi T, Yamamura T, Yokoyama E, et al. Impaired contractile motility of the gallbladder after gastrectomy. Am J Gastroenterol 81: 672, 1986. 